\title{
Characterizing the Relationship between Land Use Land Cover Change and Land Surface Temperature
}

\author{
Duy X. Tran ${ }^{a^{*}}$, Filiberto Pla ${ }^{b^{*}}$, Pedro Latorre-Carmona ${ }^{b^{*}}$, Soe W. Myint ${ }^{c^{*}}$, Mario Caetano ${ }^{d}$, \\ Hoan V. Kieu ${ }^{\text {a }}$ \\ ${ }^{a}$ Department of Geography, Hanoi National University of Education, Hanoi 10000, Vietnam \\ ${ }^{\mathrm{b}}$ Institute of New Imaging Technologies, Universidad Jaume I, 12071 Castellón, Spain \\ ${ }^{\mathrm{c}}$ School of Geographical Sciences and Urban Planning, Arizona State University, Tempe, Arizona 85287-0104 \\ dInstituto Superior de Estatística e Gestão de Informação, Universidade Nova de Lisboa (ISEGI-NOVA), 1070- \\ 312 Lisboa, Portugal
}

E-mail addresses: txduy@hnue.edu.vn (D.X. Tran), pla@uji.es (F. Pla), latorre@uji.es (P.

Latorre-Carmona), soe.myint@asu.edu (S.W. Myint)

\begin{abstract}
Exploring changes in land use land cover (LULC) to understand the urban heat island (UHI) effect is valuable for both communities and local governments in cities in developing countries, where urbanization and industrialization often take place rapidly but where coherent planning and control policies have not been applied. This work aims at determining and analyzing the relationship between LULC change and land surface temperature (LST) patterns in the context of urbanization. We first explore the relationship between LST and vegetation, man-made features, and cropland using normalized vegetation, and built-up indices within each LULC type. Afterwards, we assess the impacts of LULC change and urbanization in UHI using hot spot analysis (Getis-Ord $\mathrm{Gi}^{*}$ statistics) and urban landscape analysis. Finally, we propose a model applying non-parametric regression to estimate future urban climate patterns using predicted land cover and land use change. Results from this work provide an effective methodology for UHI characterization, showing that (a) LST depends on a nonlinear way of LULC types; (b) hotspot analysis using Getis Ord $G i^{*}$ statistics allows to analyze the LST pattern change through time; (c) UHI is influenced by both urban landscape and urban development type; (d) LST pattern forecast and UHI effect examination can be done by the proposed model using nonlinear regression and simulated LULC change scenarios. We chose an inner city area of Hanoi as a case-study, a small and flat plain area where LULC change is significant due to urbanization and industrialization. The methodology presented in this paper can be broadly applied in other cities which exhibit a similar dynamic growth. Our findings can represent an useful tool for policy makers and the community awareness by providing a scientific basis for sustainable urban planning and management.
\end{abstract}

Keywords: Urban heat island, Land use land cover change, Kernel ridge regression, Urbanization 


\section{Introduction}

The increase in the heat storage capacity of urban surfaces creates so-called urban heat islands (UHI), in which built up areas are hotter than nearby rural areas (Oke, 1982; Taha, 1997; Rizwan et al., 2008). This local difference in temperatures creates a negative impact on people and environment because it hampers air quality, increases energy consumption, loses biological control, and affects people's health (Kikegawa et al., 2003; Grimmond, 2007; Meineke et al., 2014; Plocoste et al., 2014). Advances in thermal remote sensing, geographical information systems (GIS), and statistical methods have enabled the research community to characterize and examine UHI versus landscape relationship. A great number of studies that deal with UHI analysis have been carried out, providing a significant feedback to policy makers and researchers (Quattrochi and Luvall, 1999; Yuan and Bauer, 2007; Rizwan et al., 2008; Junxiang et al., 2011; Kumar et al., 2012; Radhi et al., 2013; Myint et al., 2013; Zhou et al., 2014; Adams and Smith, 2014; Coseo and Larsen, 2014; Song et al., 2014; Chun and Guldmann, 2014; Rotem-Mindali et al., 2015; Kourtidis et al., 2015). Besides air temperature, LST derived from remote sensing data is unique source of information in order to define surface urban heat islands and it has been widely used as indicator for UHI research (Weng and Schubring, 2004; Weng, 2009; Imhoff et al., 2010). With the introduction of thermal remote sensing, LST information is available from a series of satellite sensors (such as Landsat, MODIS, and ASTER) that cover a wide range of the earth surface. Compared to air temperatures collected from weather stations, thermal imagery provides full spatial coverage at various temporal scales (Myint et al., 2013). In addition, LST derived from remote sensing imagery might be better to show the hottest and coolest areas as compared to temperature collected from urban weather station, which is located in the tree park-like surroundings (Nichol and To, 2012). Surface temperature also has a direct interaction with LULC characteristics (Quattrochi and Luvall, 1999). Therefore, the analysis of the relationship between LULC and LST is crucial in order to understand the effects of LULC on UHI.

Exploring the spatial pattern of UHI is important in understanding how the distribution of LULC and changes in that distribution influence LST. However, using absolute LST values presents the main challenge. Absolute LST can be used to characterize UHI on a particular date but, in principle, it is not appropriate to use it to compare the UHI spatial patterns through time. Comparing absolute LST values acquired on different dates under different atmospheric conditions cannot properly quantify UHI trends from a spatio-temporal perspective. Walawender et al. (2013) proposed the use of normalized LST to investigate the LST spatial distribution in relation to LULC. This guarantees that LST values retrieved from different images are comparable. However, LST values of locations/pixels are not independent but are correlated with the LST of its neighboring pixels (Song et al., 2014). In this case, normalized LST cannot deal with spatial autocorrelation problems. Therefore, the effect of spatial autocorrelation must also be considered when comparing UHI patterns through time. 
Simulation of future surface temperatures based on LULC plays an important role in mitigating UHI effects. Such understanding can be used to adapt new strategies and policies in land use planning and urban design that reduces the UHI effect. Linear regression has been commonly used in many studies to gain insight into the landscape-UHI relationship (Yuan and Bauer, 2007; Adams and Smith, 2014; Rotem-Mindali et al., 2015; Huang et al., 2015) and has been applied to future LST prediction (Ahmed et al., 2013). However, this correlation is nonlinear due to the seasonal variability of land cover data (Owen et al., 1998; Zhou et al., 2014), the complex landscape structure (Guo et al., 2015), and urban morphology heterogeneity (Guo et al., 2016). In the case of the LST prediction, a non-linear regression method could be a better approach in order to achieve a greater insight into the LULC-UHI relationship.

Analyzing the impact of LULC change on UHI needs to consider urbanization effects. Urbanization leads to the expansion of built-up and impervious surface that intensify UHIs (Chun and Guldmann, 2014). Previous studies applied different methods such as diurnal temperature range (DTR) (Wang et al., 2007; Mohan and Kandya, 2015), land use change trajectories (Feng et al., 2013), or a surface urban heat island index (SUHI) (Dihkan et al., 2015) to quantify the effects of urbanization on UHI. These studies were successful in demonstrating the contribution of urban growth to the UHI effect as well as investigating the differences in UHI between urban and rural areas. However, applying these methods could not provide insight into the effect of urban development types on UHI. Urban growth can occur in different ways, such as including infill, extension, or leapfrog development (Angel et al., 2012). It is crucial to examine how UHI is affected by different spatial patterns of urban growth. For urban planners, understanding which kinds of urban expansion exacerbate or mitigate impacts on UHIs can contribute significantly to UHI mitigation strategy.

The main contributions of the present work are directed to provide tools for a reliable analysis of LST patterns on the UHI effect and develop methodologies for predicting urban climate patterns in relation to LULC changes, exploiting the relationship between LULC and LST through time. Therefore, the objectives of this work are to (i) explore the relationship between LST and main LULC types (vegetation, man-made features, cropland) using normalized vegetation and built-up indices within each LULC type, (ii) assess the impact of LULC change and urbanization on UHI using hot spot analysis (Getis-Ord Gi* statistics) and urban landscape analysis, and (iii) apply non-parametric regression using kernel ridge regression (KRR) to estimate future urban climate patterns using the predicted changes in land cover and land use. An inner city area of Hanoi was selected to implement the proposed methodology because it has experienced fast LULC change and urbanization. The results from this study will support the effectiveness of the methodology in UHI characterization and providecrucial feedback to policy makers and urban planners in developingUHI mitigation strategies. 
The paper is structured as follows. Section 2 briefly describes the study area. Section 3 explains the methodology and data used to infer the LST as a function of the LULC spatial distribution. Section 4 presents the main results and discussion about the LULC-UHI relation and LST prediction results for the Hanoi city. Conclusions are given in Section 5.

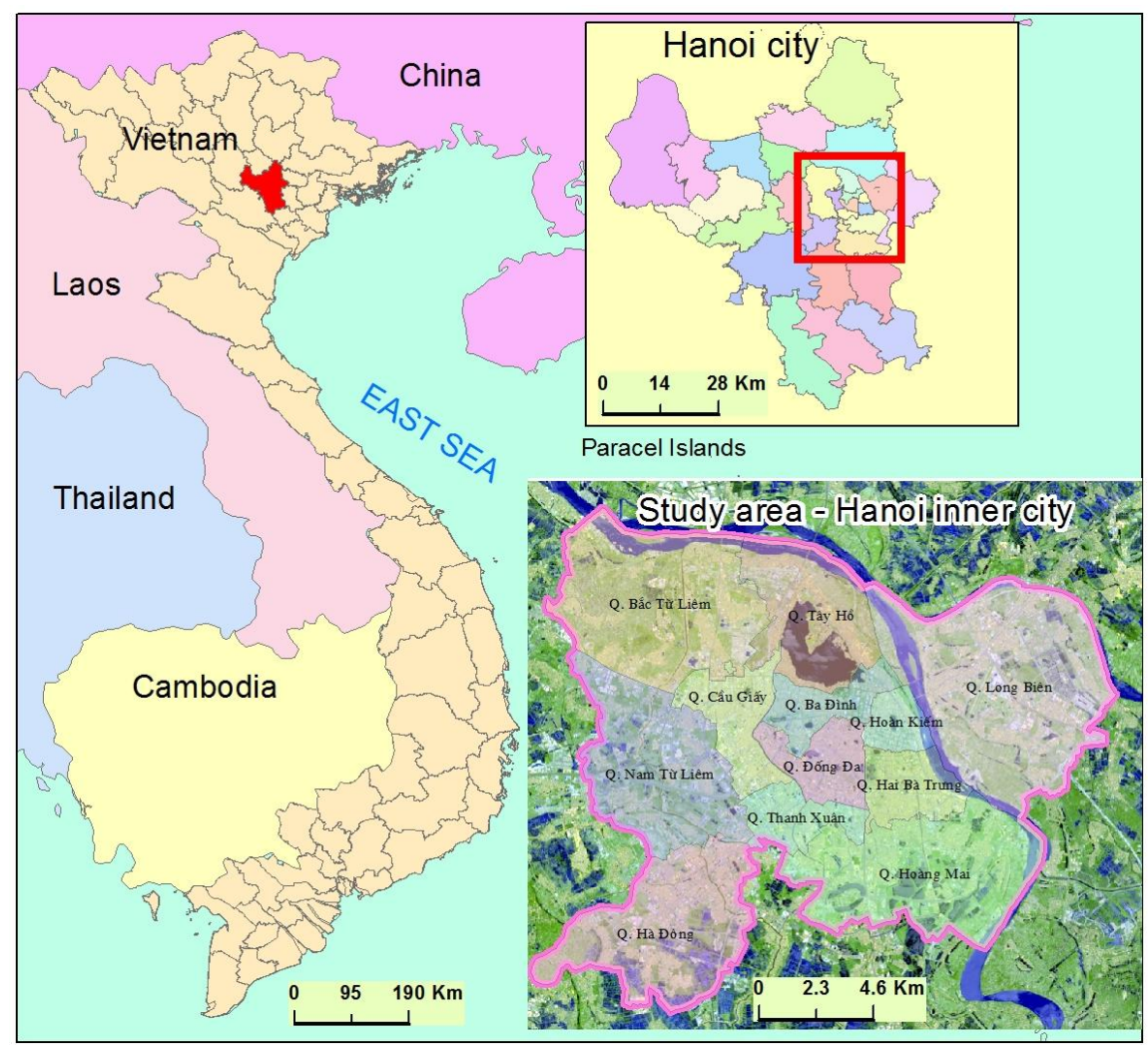

Figure 1: Map of Vietnam, Hanoi, and Hanoi inner city

\section{Study area}

The study area, Hanoi inner city, is a small and flat plain located in the center of the Red river delta, the second largest delta in Vietnam (Figure 1). Hanoi inner city covers approximately $304.3 \mathrm{~km}^{2}$ (HSO, 2013a) and has an average elevation of less than $10 \mathrm{~m}$ above sea level (Yonezawa, 2009). This area was selected as a case study because it is undergoing rapid LULC change and urbanization in addition to having extremely hot summers, which is strongly linked to the UHI effect.

Located within the warm humid subtropical climate zone, the city has a typical climate of northern Vietnam with hot, humid summers and cold, dry winters. The summer season starts in May and ends in August, during which the average temperature is $29{ }^{\circ} \mathrm{C}$ (NCHMF, 2015). As a low altitude area, combined with the impact of the Foeln (a type of dry, warm, downslope wind occurring on the leeward side of a mountain range), the city often experiences several hot periods during the summer time. This area has suffered unusual hot temperatures during the last few years. On 16 June 2010 , the mean temperature in the city reached $34.6{ }^{\circ} \mathrm{C}$ (a 
night temperature of $30.4{ }^{\circ} \mathrm{C}$ and a day temperature of $39.6{ }^{\circ} \mathrm{C}$ ), which was the highest recorded value since 1961 (NCHMF, 2015). On 28 May 2015, the temperature exceeded $40{ }^{\circ} \mathrm{C}$, which was the highest temperature since the beginning of historical records (NCHMF, 2015).

Urbanization was faster in and around Hanoi inner city than in other surrounding areas. While the study site covers only $9 \%$ of the total area of Hanoi city, this small area contains more than $40 \%$ (2.9 million people) of the city population and around $20 \%\left(140 \mathrm{~km}^{2}\right)$ of the city urban land (HSO, 2013a, 2013b). Urbanization has led to the acquisition of agricultural land, which in turn has resulted in land use changes, subsequently increasing the built-up area. The transformation between different LULC types associated with urban expansion will crucially influence the LST pattern and the magnitude of UHI effect. According to socioeconomic planning from the Vietnamese government, urban area will occupy more than $60 \%$ of the city land use structure in 2030 (VGP, 2016). In accordance with negative climate change impacts (Niem et al., 2013), UHI will be one of the key challenges for the city development.

\section{Data sources and methods}

\subsection{Data used}

Surface reflectance high level data products images including Landsat 5 Thematic Mapper (TM), Landsat 7 Enhanced Thematic Mapper Plus (ETM+), and Landsat 8 Operational Land Imager (OLI) acquired on 5 May 2003, 24 May 2007 and 1 July 2015 are the main data sources in this research (Table 1). These freely accessible images are processed by NASA which generates radiometric calibration and atmospheric correction algorithms (level-1 products http://earthexplorer.usgs.gov/). Satellite images were used to derive LULC classification and LST retrieval. A limitation of this image dataset is that the images were acquired at around 10:00 AM Hanoi time. At that time, LST values are low (approximately3-6 ${ }^{\circ} \mathrm{C}$ lower than maximum LST, which occurs at 1:00 PM). However, this issue did not significantly affect the results because the research focused on the UHI pattern rather than the absolute value.

In addition to satellite images, this research also incorporated information from institutions and organizations of the Vietnamese government, including the General Statistics Office (GSO), the Hanoi Statistics Office (HSO), the Ministry of Natural Resources and Environment (MONRE), and the National Centre for Hydro-Meteorological Forecasting (NCHMF).

Table 1: Remote sensing data used in the study

\begin{tabular}{|c|c|c|c|c|c|}
\hline Sensors & Dates & Path/row & Bands & $\begin{array}{c}\text { Resolution } \\
\text { (meters) }\end{array}$ & Source \\
\hline \multirow{2}{*}{ Landsat $7 \mathrm{ETM}^{+}$} & \multirow{2}{*}{$05 / 05 / 2003$} & \multirow{2}{*}{$127 / 45$} & $3,5,7$ & 30 & \multirow{2}{*}{ - earthexplorer.usgs.gov } \\
\hline & & & 6 & $60 \times(30)$ & \\
\hline \multirow[t]{2}{*}{ Landsat 5 TM } & \multirow[t]{2}{*}{$24 / 05 / 2007$} & \multirow[t]{2}{*}{$127 / 45$} & $3,5,7$ & 30 & \multirow{2}{*}{ - earthexplorer.usgs.gov } \\
\hline & & & 6 & $120 \times(30)$ & \\
\hline
\end{tabular}




\begin{tabular}{lllll}
\hline Landsat 8 OLI & $01 / 07 / 2015$ & $127 / 45$ & $4,6,7$ & 30 \\
\cline { 3 - 4 } & & 10 & $100 \times(30)$ & earthexplorer.usgs.gov \\
\hline
\end{tabular}

$\times \overline{\text { Thermal band is acquired at different resolution, but products were resampled by NASA to 30-meter }}$ resolution pixels.

\subsection{Research methods}

\subsubsection{LULC classification and land use change prediction}

A mixture of Gaussian classification approaches (with a maximum likelihood final decision strategy) (Tempfli et al., 2009) was used to obtain the LULC distribution in the study area. Composite imagery with false color band combination of bands $(7,6,4)$ in Landsat 8, $(7$, 5,3 ) in Landsat 5 TM and Landsat 7 ETM+ was used to obtain better visualization of the urban environments. Training samples for each LULC type were determined by comparing the false color composition images, Google Earth information and in-situ information. The classification included in eleven LULC classes within six categories: vegetation, agriculture (high-density cropland, low-density cropland, and wetland), urban (high-residential area, low-residential area, industrial and commercial land, and impervious surface), vacant land, water, and sandbars.

To improve the classification results, a two-stage classification strategy was implemented: (1) a majority filter was applied to remove misclassified pixels; and (2) more accurate water and sandbar data (acquired by other methods) was integrated into the filtered image. In particular, water areas were determined by using the normalized difference water index (NDWI; Xu, 2006) whereas sandbars were manually fixed. The accuracy of each classification was assessed by uploading 350 points taken from each classified image to Google Earth Pro to compare their similarity. The "view historical imagery" tool in Google Earth Pro was used to find the best possible referenced image for each year. Based on this, the overall accuracy (the percentage of correctly classified pixels out of all pixels sampled for all classes), producer's accuracy (the percentage of a particular LULC type on the ground is correctly classified in the map), user's accuracy (the percentage of a class on the map that matches the corresponding class on the ground) and kappa index (the degree of matching between reference data set and classification) were calculated to evaluate the accuracy of the classification. The classified images were then compiled by using the overlay tool in ArcGIS to assess land use change from 2003 to 2015.

In order to make LULC predictions, land change prediction was applied using the multi-layer perceptron (MLP) neural network (Palit and Popovic, 2006) and a Markov chain models (Baker, 1989). Future LULC was predicted using a process that included two main steps: (1) modeling the potential for change and (2) predicting change. First, five potential variables (distance to the main road, distance to the existing urban center, population, distance to water bodies, and elevation) were used to model the LULC transition from 2003 to 2015. The transition map was inferred by applying the MLP neural network, which is the most 
widespread network structure for efficient time -series forecasting (Palit and Popovic, 2006). MLP neural network training is based on the backpropagation (BP) training strategy. Based on a set of LULC output values, the network learns to create a potential map from potential inputs for each transition. For instance, the areas closer to main roads, the urban center, water bodies, and with a higher elevation may be more suitable for urban growth than others.

In a second stage, Markov chain analysis (Baker, 1989) was applied to model future LULC by specifying the prediction date. The Markov chain model determines the amount of change over a specific time period by comparing two land cover maps from two different times. The procedure results in a transition probability matrix that records the probability of each land cover category to change to every other category. In the simulation of future LULC change, two different scenarios were considered: slow (low) and fast (high) urban growth. In the low urban growth scenario, the urban expansion prediction is based on observations over the period 2003-2015 (which showed an expansion rate of 1.1\% per year). In the high urban growth scenario, the simulation applied the prediction from the Vietnamese Government Planning office (VGP, 2016), which is higher than the current urbanization speed (1.5\% per year). The constraint areas were set to avoid some unreasonable transformations, for example from water or sandbars to urban. Low land/wetland and vegetation areas were not used in order to obtain better prediction results.

\subsubsection{Land surface temperature retrieval}

Table 2 presents all the parameters introduced in this section. The thermal infrared bands of different types of Landsat images (band 6 of Landsat 5 TM, Landsat 7 ETM+ and band 10 of Landsat 8 ) were used to estimate the LST of Hanoi inner city.

Table 2: The parameters in LST retrieval

\begin{tabular}{|c|c|}
\hline Parameters & Definition \\
\hline$L_{\lambda} / L_{T O A}$ & the spectral at-sensor radiance (top of the atmosphere) \\
\hline$G_{\text {re_scaled }}$ & $\begin{array}{l}\text { the rescaled gain (the data product "gain" contained in the Level } 1 \text { product } \\
\text { header or ancillary data record) }\end{array}$ \\
\hline$B_{\text {re_scaled }}$ & $\begin{array}{l}\text { the rescaled bias (the data product "offset" contained in the Level } 1 \text { product } \\
\text { header or ancillary data record) }\end{array}$ \\
\hline$Q_{\text {Cal }}$ & the quantized calibrated pixel value \\
\hline$L_{\operatorname{Min}, \lambda}$ & the spectral radiance scaled to QCALMIN \\
\hline$L_{\text {Max, } \lambda}$ & the spectral radiance scaled to QCALMAX \\
\hline$Q_{\text {Cal,Min }}$ & the minimum quantized calibrated pixel value (corresponding to $L_{\mathrm{Min}, \lambda}$ ) \\
\hline$Q_{\text {Cal,Max }}$ & the maximum quantized calibrated pixel value (corresponding to $L_{\mathrm{Max} \lambda}$ ) \\
\hline$M_{L}$ & $\begin{array}{l}\text { the radiance multiplicative scaling factor for the band } \\
\left(R A D I A N C E \_M U L T \_B A N D \_n \text { from the metadata) }\right.\end{array}$ \\
\hline$\Delta_{L}$ & the radiance additive scaling factor for the band $\left(R A D I A N C E \_A D D \_B A N D \_n\right.$ \\
\hline
\end{tabular}




\begin{tabular}{ll}
\hline & from the metadata) \\
$\tau$ & the atmospheric transmission \\
$L_{T}$ & the emissivity of the surface \\
$L_{u}$ & the radiance of a blackbody target of kinetic temperature $T$ \\
$L_{d}$ & the upwelling or atmospheric path radiance \\
$\mathrm{T}$ & the downwelling or atmospheric path radiance \\
$K_{1}, K_{2}$ & the apparent surface temperature in Kelvin \\
\hline
\end{tabular}

LST retrieval involves the following steps (Landsat 7, 2011; Landsat 8, 2015).

(1) First, the pixel values were converted from digital number units to radiation values (Landsat $5 \mathrm{TM}$ and Landsat 7 ETM+):

$$
L_{\lambda}=G_{\text {re_scaled }} \cdot Q_{\text {Cal }}+B_{\text {re_scaled }}
$$

which may also be expressed as:

$$
L_{\lambda}=\frac{L_{M a x, \lambda}-L_{M i n, \lambda}}{Q_{C a l, M a x}-Q_{C a l, M i n}} \cdot\left(Q_{C a l}-Q_{C a l, M i n}\right)+L_{M i n, \lambda}
$$

In the case of Landsat 8:

$$
L_{\lambda}=M_{L} \cdot Q_{C a l}+\Delta_{L}
$$

(2) Then, the TOA radiance was converted to surface-leaving radiance by removing the effects of the atmosphere in the thermal region (Barsi et al., 2005; Yuan and Bauer, 2007; McCarville et al., 2011):

$$
L_{T O A}=\tau \varepsilon L_{T}+L_{u}+(1-\varepsilon) L_{d}
$$

where the atmospheric transmission $(\tau)$, and the upwelling $\left(L_{u}\right)$, and downwelling $\left(L_{d}\right)$ radiance values were assessed using the Atmospheric Correction Parameter Calculator online tool (http://atmcorr.gsfc.nasa.gov). This tool applies the National Centers for Environmental Prediction (NCEP) modeled atmospheric global profiles for a particular date, time, and location as the input data (Barsi et al., 2003). The surface emissivity $(\boldsymbol{\varepsilon})$ was assessed using the method proposed by Sobrino et al. (2004).

(3) Finally, the surface-leaving radiance was converted to apparent surface temperature using the Planck curve specific Landsat implementation:

$$
T=\frac{K_{2}}{\ln \left(\frac{K_{1}}{L_{T}}+1\right)}
$$

\subsubsection{Regression analysis}


Single and multiple linear regression analysis were initially applied to determine the correlation between LST and LULC. Normalized difference vegetation index (NDVI), normalized difference built-up index (NDBI), and LST values were extracted from each pixel in the study area for each point data type. These points were used as the input for the linear regression model. This model gives a general idea about the correlation/relationship between LST and LULC.

However, in the case of LST prediction several LULC variables were considered that may generate a complex structure. Thus, a better and more flexible regression method is needed to determine the local variations in the LULC-LST correlation. Hence, a non-linear regression method using the KRR algorithm (Saunders et al., 1998) was applied to predict the future surface temperature. Ridge regression is a generalization of least squares regression. For instance, in the case of linear regression, assume that the aim is to fit the linear function $y=\omega \cdot x$ to the data. Linear regression aims at assessing $\omega=\omega_{0}$ so that the following function is minimized:

$L_{T}(\omega)=\sum_{i=1}^{T}\left(y_{i}-\omega \cdot x_{i}\right)^{2}$

where $\left\{\left(x_{1}, y_{1}\right), \ldots,\left(x_{T}, y_{T}\right)\right\}$ is the training set group of points. Ridge regression slightly modifies this equation to:

$L_{T}(\omega)=a\|\omega\|^{2}+\sum_{i=1}^{T}\left(y_{i}-\omega \cdot x_{i}\right)^{2}$

where $a$ is a fixed positive constant.

There are different strategies to obtain the $\{(a, \omega)\}$ parameters. One of them consists of applying constrained minimization methods to the so-called dual version of Eq. (7) (see Saunders etal., 1998 for further details). Under this framework, this estimation depends on the dot products of the $x$ elements, i. e., $x_{i} \cdot x_{j}$.

KRR is a modification of Eq. (7) in such a way that non-linear functions can be implicitly fitted. It can be shown (Saunders et al., 1998) that in this case the aim is related to the estimation of a function (mapping) $\phi$ that "transforms" the training points to higher dimensional spaces $\left(x_{i} \rightarrow \phi\left(x_{i}\right)\right)$ where the problem may be tackled as a linearization of the non-linear lower dimensional space where the $x_{i}$ points lie. It can also be shown that the dot products of the $x$ elements, i. e., $x_{i} \cdot x_{j}$ are transformed into $\phi\left(x_{i}\right) \cdot \phi\left(x_{j}\right)$ and this group of products forms the so called transformation kernel.

\subsubsection{LST prediction model}

The LST prediction process consists of the following stages (Figure 2). The first part is generation of a spatial model that allows inferring the LULC temporal dynamics (previously mentioned in the land use change prediction method). The result of this calculation is future LULC at different scenarios. 
The second part is generation of an LULC-LST model. For the LULC variable, the percentage cover of five classified land use types (urban land, vegetation, cropland, water, and vacant land) was calculated using three different window sizes $(5 \times 5,10 \times 10$, and $20 \times 20$ meaning resolution of 150,300 , and $600 \mathrm{~m}$, respectively). Previous works on topics related to appropriate resolution for measuring the LST-LULC relationships suggest that the suitable resolution is at 660-720 m (Song et al., 2014). However, the model was stopped at $600 \mathrm{~m}$ instead of reaching larger window size because the study area used in the experiments is quite small so a lower resolution would not be able to provide an appropriate result for practical purposes (such as urban planning). In addition, it was assumed that the lower resolution would lead to a too generalized result that would reduce the accuracy. For the LST variable, the mean surface temperature value for the same spatial resolution as was made for LULC was extracted. Then, KRR was trained to infer the relationship between LST and all five LULC variables at different spatial resolutions.

The final stage consists of using LST data from 2003 and 2007, and LULC from 2015 in window sizes of $5 \times 5,10 \times 10$, and $20 \times 20$ to predict LST in 2015 . The mean surface temperature was extracted for the same spatial resolution as it was made for LULC. Then, we trained KRR to infer the relationship between LST and all five LULC variables at different spatial resolutions. The results were compared to choose which data and resolution provided the best LST input/training data results. After deciding the best-input time and resolution, the future LST prediction was performed, based on the simulation of future LULC scenarios.

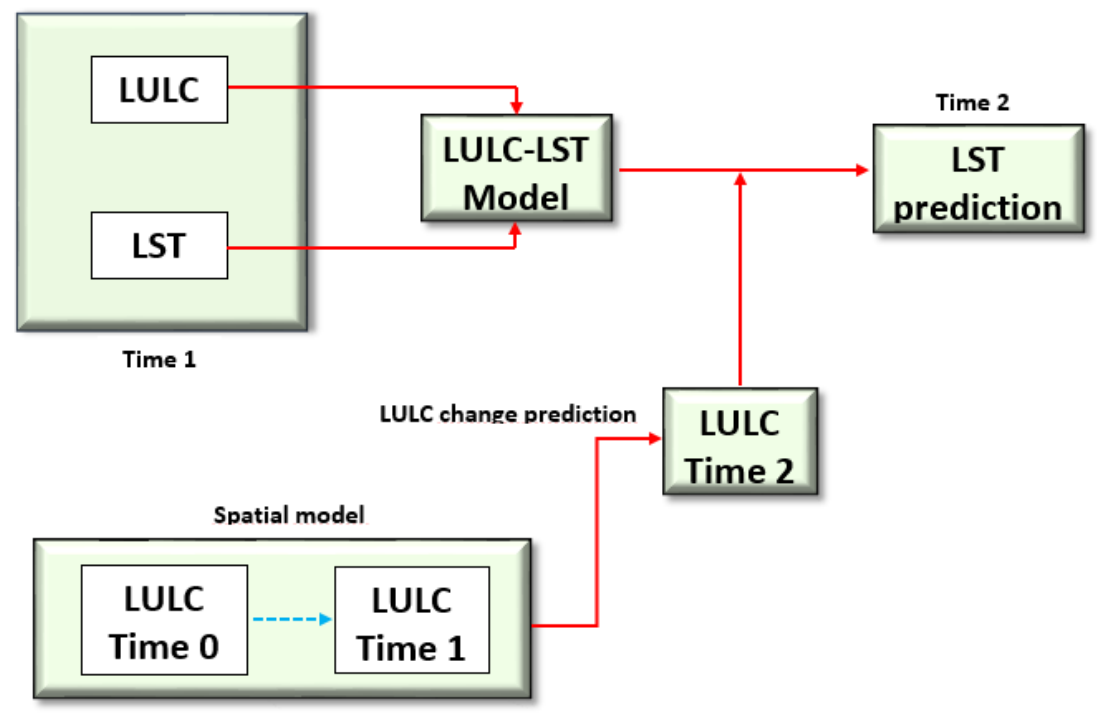

Figure 2: Diagram of the methodology used for LST prediction

\subsubsection{Hot spot analysis using Getis Ord Gi* statistic}

The hot spot analysis (Getis-Ord Gi*) tool in the ArcGIS software, developed by Environmental Systems Research Institute (ESRI) was applied to explore the spatial cluster arrangements appearing in UHI data. This technique characterizes the presence of hot spots 
(high clustered values) and cold spots (low clustered values) over an entire area by looking at each feature (LST value) within the context of its neighboring features (Ord and Getis, 1995; see Eq. (8), Eq. (9) and Eq. (10)). A feature with a high value is interesting but may not be a statistically significant hot spot. To be a statistically significant hot spot, a feature must have a high value and should also be surrounded by other features with high values. This method is a potential technique for characterization and quantification of spatial autocorrelation of remotely sensed imagery by providing a measure of spatial dependence for each pixel and indicating the relative magnitudes of the digital numbers in the neighborhood of the pixel (Wulder and Boots, 1998). The Getis-Ord Gi* local statistics is calculated using (ESRI, 2016):

$$
\boldsymbol{G}_{i}^{*}=\frac{\sum_{j=1}^{n} \omega_{i, j} x_{j}-\overline{\boldsymbol{X}} \sum_{j=1}^{n} \omega_{i, j}}{\boldsymbol{S} \sqrt{\frac{n \sum_{j=1}^{n} \omega_{i, j}^{2}-\left(\sum_{j=1}^{n} \omega_{i, j}\right)^{2}}{n-1}}}
$$

where $x_{j}$ is the attribute value for feature $j, w_{i, j}$ is the spatial weight between feature $i$ and $j n$ is equal to the total number of features and:

$\overline{\boldsymbol{X}}=\frac{\sum_{j=1}^{n} x_{j}}{n}$

and

$$
\boldsymbol{S}=\sqrt{\frac{\sum_{j=1}^{n} x_{j}^{2}}{n}-\overline{\boldsymbol{X}}^{2}}
$$

The output of the Gi* statistic returned for each feature in the dataset is a z-score. Higher positive z-score shows more intense clustering of high values (hot spot) and a smaller negative z-score represents more intense clusters of low values (cold spot). The z-score represents the statistical significance of clustering for a specified distance (90\% significant: $>1.65$ or $<-1.65$; $95 \%$ significant: $>1.96$ or $<-1.96$; $99 \%$ significant: $>2.58$ or $<-2.58$; $99.9 \%$ significant: >3.29 or <-3.29). At a significance level of 0.05 (95\%), a z-score would have to be less than -1.96 or greater than 1.96 to be statistically significant. From the statistical results, the LST pattern was divided into seven categories: very hot spot, hot spot, warm spot, not statistically significant, cool spot, cold spot, and very cold spot. In the final statistics of the hot spots and cold spots in our paper, values at $95 \%$ or higher confidence level were taken. To assess the impact of LULC change on the UHI effect, the hotspot pattern change was linked to LULC change through time. This method gives a better demonstration of the UHI effect, rather than focusing only on the high or low LST absolute values separately.

\subsubsection{Urban landscape analysis}


The urban landscape analysis tool (ULAT) developed by the Centre for Land use Education and Research (CLEAR) and the University of Connecticut (CLEAR, 2015) was employed to classify urbanized area into different classes and identify new urban development areas. This tool is based on the concept proposed by Burchfield et al. (2006) and Angel et al. (2012). The definition and calculation of these categories and types are defined as follows:

- infill is all newly developed built-up areas that are surrounded by existing built-up areas

- extension is all new built-up development intersecting with existing built-up areas

- leapfrog development is all new construction that does not intersect with built-up areas (new built-up areas that are isolated from existing urban areas)

- walking distance circle is a circle with a radius of $0.5 \mathrm{~km}$ around a given built-up pixel

- urban built-up pixels are pixels that have a majority of built-up pixels within their walking distance circle

- suburban built-up pixels are pixels that have 10 - 50\% built-up pixels within their walking distance circle

- rural built-up pixels are pixels with less than $10 \%$ built-up pixels within their walking distance circle

- fringe open space is all open space pixels within 100 meters of urban or suburban pixels

- captured open space is all open space clusters that are fully surrounded by built-up and fringe open space pixels and are less than 200 hectares in area; exterior open space consists of all fringe open space pixels that are less than 100 meters from the open countryside;

- urbanized open space consists of all fringe open space, captured open space and exterior open space pixels in the city

- rural open space consists of all open spaces that area not urbanized open spaces

The achieved results were then related to the mean LST of the extracted areas to determine how urbanization has impacted UHI in the study area.

\section{Results and Discussion}

\subsection{LULC classification and LST distribution}

A mixture of Gaussian classification approaches was applied following the strategy explained in Section 3.2.1 and the classification quality was assessed using the producer's accuracy, user's accuracy, overall classification accuracy, and kappa coefficient generated for the LULC classification accuracy assessment of the 2003, 2007, and 2015 data.

The overall classification accuracies for the 2003, 2007, and 2015 data were $93.8 \%$, $94.4 \%$, and $92.3 \%$ respectively. Water and sandbar LULC types had the highest accuracy (higher than 97\%) in all classified images. For the 2003 data, impervious surface and vegetation had the lowest user's accuracy (83.3\% and 87.5\%). For the 2007 data, industrial/commercial land was the least accurate (87.7\%). For the 2015 data, all the LULC 
types presented high accuracy ranging from $90 \%$ to $100 \%$. The kappa coefficients of these classified images were $0.93,0.94$, and 0.91 , respectively.

From the LULC classification results (see Appendices 1 to 3), it was found that urban and agriculture areas were the two main LULC types in the LULC structure of the city. Water also played an important role as it occupied more than $10 \%$ of the total land use structure. The study results showed that LULC in the study area changed significantly from 2003 to 2015. The main LULC change driver was transformation of agricultural land to urban area due to urbanization and industrialization.

Figure 3 shows the study area LST patterns in 2003, 2007, and 2015, respectively. LST ranged from $27.33{ }^{\circ} \mathrm{C}$ to $50.91{ }^{\circ} \mathrm{C}$ across the city in 2003 , from $24.66{ }^{\circ} \mathrm{C}$ to $51.86{ }^{\circ} \mathrm{C}$ in 2007 , and from $30.06{ }^{\circ} \mathrm{C}$ to $53.91{ }^{\circ} \mathrm{C}$ in 2015 . Mean LST in the region was $36.52{ }^{\circ} \mathrm{C}, 37.47{ }^{\circ} \mathrm{C}$, and $40.38{ }^{\circ} \mathrm{C}$ respectively. The LST pattern is strongly correlated with LULC distribution. A small proportion of very high LST value (dark red color) is mainly distributed on the sandbars and rooftop of the industrial/commercial building. The high LST area (heavy yellow and red color) appears as a big island surrounded by low LST regions (represented in blue). This core is in the center where the highly urbanized zone is located. There is a small transition LST area marked in light yellow between these two LST patterns. In addition, there are some small cold islands inside the hot area where the water bodies or parks located.
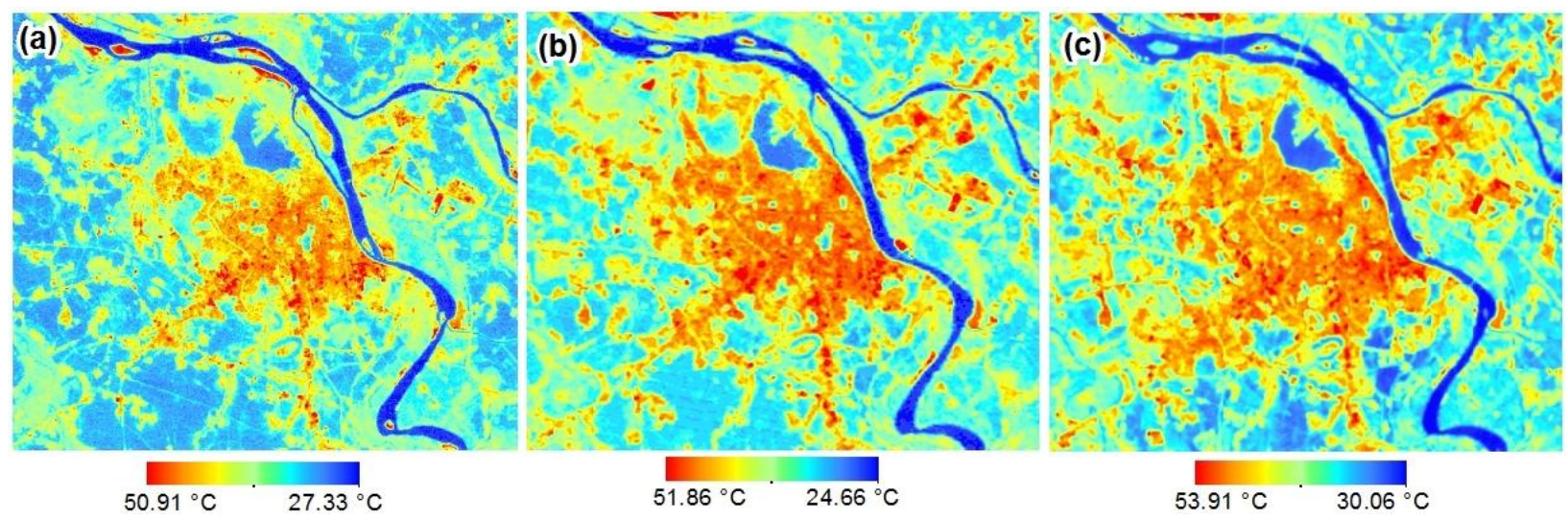

Figure 3: LST maps (degree Celsius) of Hanoi inner city in different dates (a: 5 May 2003, b: 24 May 2007 and c: 1 July 2015)

\subsection{Study of the relationship between LULC and LST}

\subsubsection{Correlation between LST and NDVI NDBI}

The first objective was to analyze the correlation between LST, NDVI, and NDBI for all LULC types in the study area. To assess this relationship, a multiple regression analysis between LST, NDVI and NDBI for all pixels in the study area except water (water area was excluded due to its special characteristics) was applied. The multiple regression model developed in the study is defined as: 
2003: $\quad L S T=42.53+14.65 N D B I-4.13 N D V I$

2007: $\quad L S T=43.35+24.45 N D B I-1.36 N D V I$

2015: $\quad L S T=44.11+16.10 N D B I-1.13 N D V I$

where:

LST is the land surface temperature (degrees Celsius);

NDBI is normalized difference built-up index

NDVI is normalized difference vegetation index

The results indicate a negative correlation between LST and NDVI and a positive correlation between LST and NDBI. This observation is very consistent with those reported by a number of previous studies (Zhang et al., 2009; Liu and Zhang, 2011; Ogashawara and Bastos, 2012; Kumar and Shekhar, 2015; Guo et al., 2015). The negative NDVI coefficient and positive NDBI coefficient from the three dates imply that within the study area, vegetation contributes to a decrease in the UHI effect while the built-up area strengthens the UHI effect. In addition, the effect of NDVI tends to be weaker. As seen in the 2003-2015 time interval, the NDVI coefficient decreased from 4.13 to 1.13 . This can be explained by analyzing the trend in the LULC change during this period. Urban area, indicated by high NDBI and low NDVI, has increased and occupied part of other low NDBI and high NDVI LULC types such as cropland, water, and vegetation.

To better understand the detailed relationship between LST and LULC, a regression model for each LULC type was constructed. The correlation between NDVI, NDBI and LST within each LULC type showed some important results. First, a general trend was seen in urban LULC in the sense that all urban LULC types were negatively correlated with NDVI and positively correlated with NDBI. This highlighted an important conclusion about the incontrovertible role of vegetation in mitigating UHI. Urban design that considers vegetation partitions would help to regulate the thermal environment (Qiao et al., 2013). City planners and policy makers should take seriously into account the "greening strategy" as it may be the most effective solution for reducing the UHI effect within a city. Nevertheless, it was discovered that water had a positive effect in relation to both NDBI and NDVI. It means mixed water with more vegetation and built-up materials (sand, gravel, soil, or rubbish) will have higher LST. We assume that polluted water might negatively contribute to the UHI effect. Therefore, further study may be needed to quantify the relationship between water quality and UHI.

However, the results are somewhat surprising in relation to the different trends observed considering the same LULC type. For example, NDVI negatively affected LST in vegetation areas in 2003 and 2007 but its effect was the opposite in 2015. Wetland and vacant land showed the same problem, i.e., the correlation was different between 2003 versus 2007 and 2015. A possible reason for this might be that vegetation in the urban area had a higher 
mean LST than vegetation areas located outside the urban area. This was strongly reflected in the 2015 data when the urban areas significantly expanded. Another possible explanation is that the NDVI data used in 2015 was acquired two months later in the year (acquired in July) than the 2007 and 2003 data (acquired in May). Thus, this might reflect seasonal variations of NDVI value depending on vegetation growth and human activities. Previous studies have reported that the correlation between LST and NDVI is subject to different NDVI value thresholds (Qiao et al., 2013; Guo et al., 2015). At a specific change of NDVI, it may generate a counterintuitive inverse trend in the model.

Therefore, it was concluded that the relationship between NDVI, NDBI, and LST is not always linear. It varies between each LULC type and changes based on geographic location/pattern and season. To obtain better insight into the LULC-LST correlation, these local differences need to be explained. We suggest that the linear regression model can be useful in discovering the general trend as well as providing the big picture of the relationship between LST and LULC. However, a linear relationship is not always the best choice when considering an analysis at a more local level.

\subsubsection{Impact of LULC change on UHI}

Getis-Ord Gi* statistics has been widely applied in hot spot identification in research areas such as crime analysis (Craglia et al., 2000), incident management (Songchitruksa and Zeng, 2010), heat vulnerability assessment (Wolf and McGregor, 2013), and natural disaster examination (Gajović and Todorović, 2013). In our study, this method was used to assess the impact of LULC change on the UHI. By applying the Getis-Ord Gi* statistics, hotspot maps of the Hanoi inner city were created on three different dates (Figure 4). This may provide a better understanding of the city's UHI effect. The identification of hot spot or cold spot areas by such method does not depend on whether the mean surface temperature is high or low. This implies that the effect of different LST values throughout time is reduced, and therefore the results can more confidently be compared.

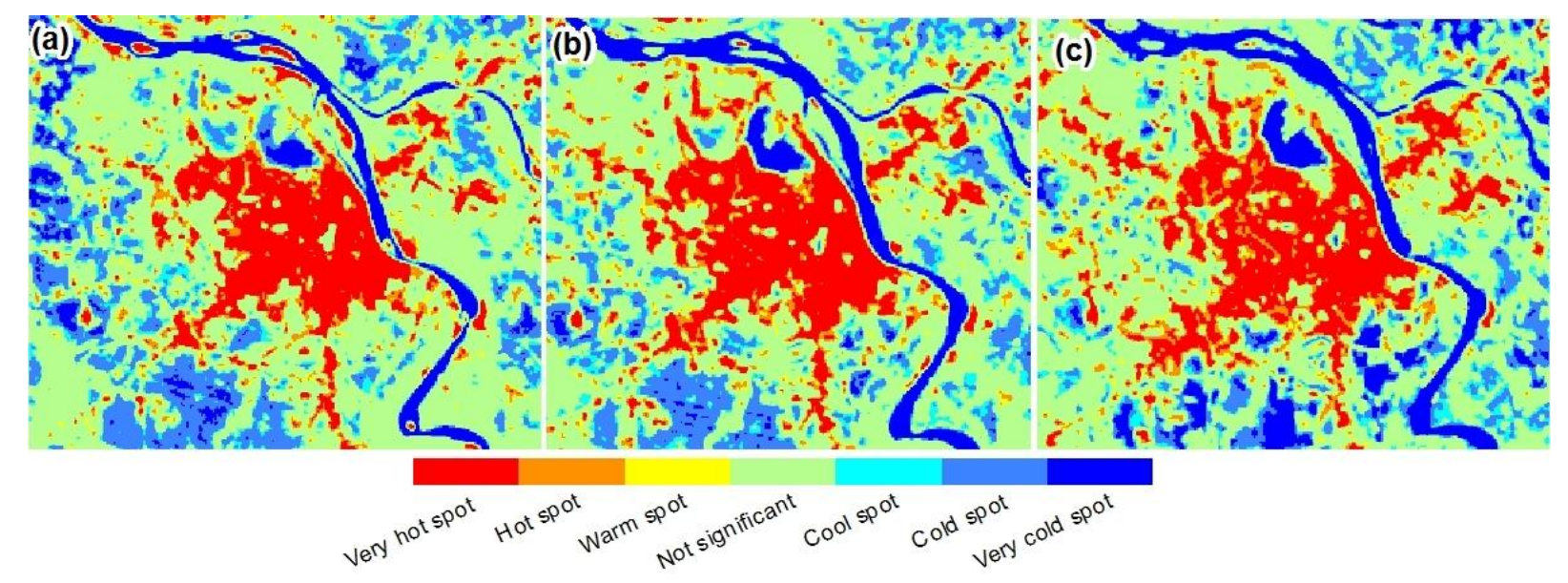


Figure 4: Hotspot analysis of Hanoi inner city in different dates (a: 5 May 2003, b: 24 May 2007 and c: 1 July 2015)

The maps show that hot regions are highly clustered in the urban center, along main roads and industrial zones. The cold regions correspond to areas of extensive vegetation, rivers, and lakes. Hot spot regions tend to expand through time. It is also recognized that when LST increases, some "not statistically significant" areas tend to become cold spots. This is represented by the transformation of many lakes and parks inside urban centers in 2015 to cold spots.

In general, hot spots occupy larger area than cold spots. More than $20 \%$ of the city is always warmer whereas less than $10 \%$ of the city is always colder than the mean zonal LST. The hottest land cover type is urban land while the coldest type is water. Water bodies make up the largest proportion of cold spots, contributing to more than $50 \%$ to the total cold spot area. Agriculture plays the second most significant role in supplying cold spots next to water bodies. Vegetation has a small contribution to the number of cold spots. Hot spots tend to increase (from $27.95 \%$ in 2003 to $34.61 \%$ in 2015) whereas cold spots tend to decrease (from $13.48 \%$ in 2003 to $12.21 \%$ in 2015) through time, but these trends differ between LULC types.

It is therefore concluded that LST spatial pattern is highly affected by the LULC structure. The transformation between different LULC types (especially urban expansion) has intensified the UHI effect by increasing and having a strong effect on the number and distribution of the hot spots. Land use planning and management therefore plays a key role in the UHI reduction. This was clearly demonstrated by Luyssaert et al. (2014) where they showed that both land management and land cover change have the same impacts on surface temperature.

\subsubsection{UHIs and urban growth}

In general, a quick analysis of the mean LST of the corresponding LULC areas extracted by the urban landscape analysis shows that urban built-up is the hottest area whereas rural open land is the coldest area (Table 3). Thus, the LST spatial pattern is directly correlated to the transition of different zones. LST decreases from the hottest urban core area to the suburban area, then the rural built-up area, and reaches the lowest mean LST at the rural open land. Within the urban zone, the urbanized open land has lower LST compared to urban and suburban built-up areas. This shows the important role of open areas such as parks, public spaces, and other non-built-up areas in reducing UHI effects.

Table 3: Mean LST in different urban landscape $\left({ }^{\circ} \mathrm{C}\right)$

\begin{tabular}{lccc}
\hline Urban landscape & $\mathbf{2 0 0 3}$ & $\mathbf{2 0 0 7}$ & $\mathbf{2 0 1 5}$ \\
\hline Urban built-up & 42.58 & 44.57 & 45.61 \\
Suburban built-up & 40.27 & 41.43 & 42.80 \\
Rural built-up & 38.86 & 38.69 & 40.13
\end{tabular}




$\begin{array}{llll}\text { Urbanized open land } & 39.02 & 40.10 & 41.43 \\ \text { Rural open land } & 35.73 & 35.64 & 38.19\end{array}$

Regarding new urban development types, infill development has the highest mean temperature while leapfrog development has the lowest temperature (Table 4). This can be explained in two ways. First, urban infill areas are surrounded by high LST land use type such as built-up areas, which positively influences the infill area's LST. In contrast, leapfrog urban areas are surrounded by other land use types with lower LST such as agriculture land. This helps to reduce the leapfrog area mean LST. In addition, leapfrog urban areas often have good planning policies that incorporate an appropriate percentage of public areas like parks and lakes. This "good" LULC structure contributes to the decrease in LST. An urban area under extension often has higher LST than a leapfrog area and lower LST than infill area because its surrounding areas include both built-up areas and other LULC types. The correspondence of differences in mean LST to urban development types provides important feedback. Process of filling up the open land in a city has many negative impacts. It critically increases the urban warming effect within the city and reduces living conditions by decreasing public space. In such a situation, UHI cannot be avoided, but its effect can be reduced by applying more appropriate urban development types. Constructing new urban areas with proper LULC structure instead of filling up the existing urban space is an efficient solution for reducing the UHI effect.

Table 4: LST in different urban development types $\left({ }^{\circ} \mathrm{C}\right)$

\begin{tabular}{lccc}
\hline & $\mathbf{2 0 0 3} \mathbf{- 2 0 0 7}$ & $\mathbf{2 0 0 7 - 2 0 1 5}$ & $\mathbf{2 0 0 3} \mathbf{- 2 0 1 5}$ \\
\hline Infill & 42.98 & 44.58 & 45.14 \\
Extension & 40.93 & 42.69 & 43.41 \\
Leapfrog & 38.34 & 40.21 & 40.94 \\
\hline
\end{tabular}

To initially analyze the relationship between urban cover and mean area LST, a zonal statistics tool in ArcGIS was used to estimate the mean LST at each percentage of urban area (from 0 to 100\%). A linear regression was then applied to explore the correlation between LST and urban cover (Figure 5). 

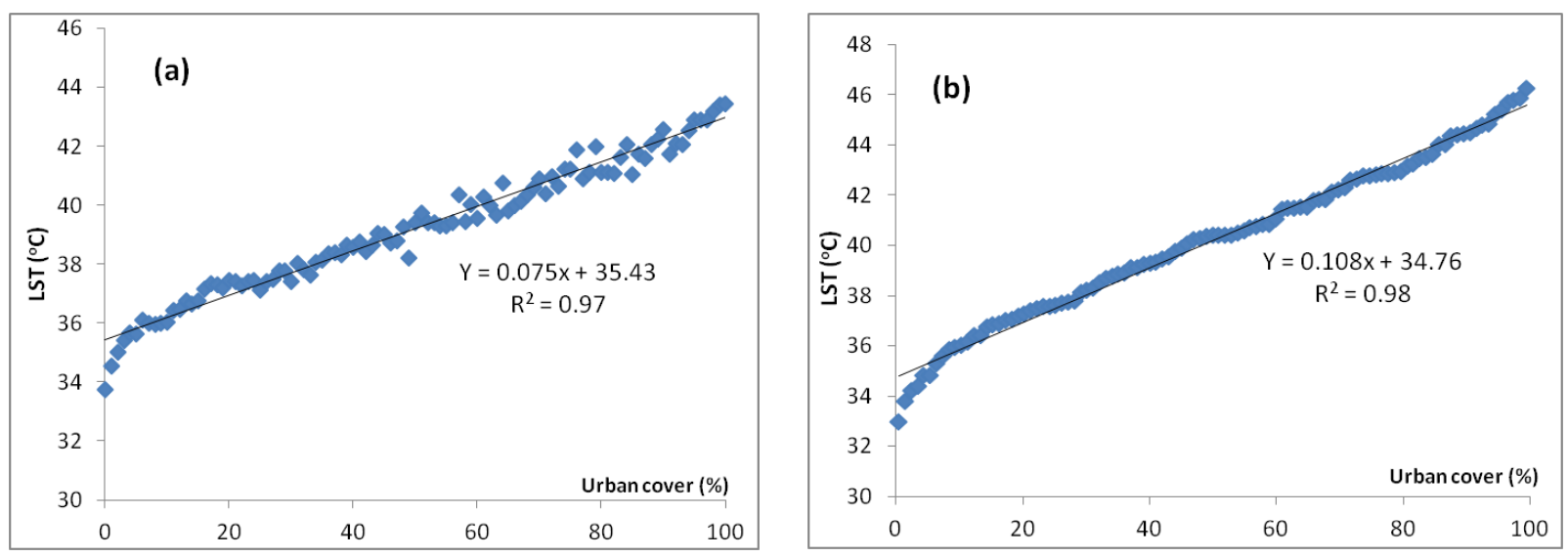

Figure 5: Linear regression analysis between percent urban area and surface temperature in a: 2003, b: 2007, and c: 2015

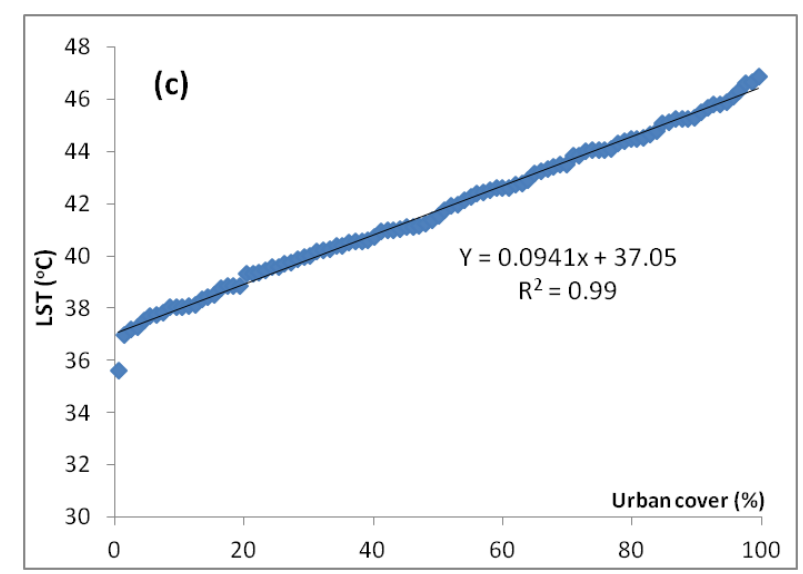

The regression models for the three dates (Figure 5) show a strong linear relationship $\left(R^{2}\right.$ around 0.97 to 0.99$)$. The results reveal that every increase of $1 \%$ in urban area will increase surface temperature between 0.075 and $0.108{ }^{\circ} \mathrm{C}$. In total, urban area can contribute to an increase of 7.5 to $10.8{ }^{\circ} \mathrm{C}$ in LST within the study area. This observation is crucial in the sense that decreasing urban density is also an effective UHI mitigation solution. Urban planners should consider configurations of urban landscape structure with lower urban density and more green space.

\subsection{LST prediction and future LST patterns}

\section{LST prediction validation}

One of the main contributions of this work is the proposed methodology to use temperature prediction to estimate future LST patterns to model and estimate UHI according to different LULC change scenarios, in order to use it as an analysis tool for urban and landscape planning to try to avoid the UHI disruptive effects in local climate and human welfare.

To this end, KRR-based method introduced in section 3.2.3 was applied to predict LST and validate the proposed technique with real data. Therefore, in order to predict absolute LST in 2015, KRR-based method was trained using the data corresponding to 2003 and 2007. LST was predicted using window sizes of $5 \times 5,10 \times 10$, and $20 \times 20$. These window sizes were chosen in order to obtain mean LST analysis areas multiples of the $600 \mathrm{~m}$ resolution. 
In order to assess the prediction quality, the level and percentage of matched LST pixels between predicted value and test value in the study area (Table 5) were compared.

Table 5: Assessment of the difference between predicted LST and test LST (area percentage)

\begin{tabular}{|c|c|c|c|c|c|c|}
\hline \multirow[b]{2}{*}{ Window size } & \multicolumn{3}{|c|}{2003 predict 2015} & \multicolumn{3}{|c|}{2007 predict 2015} \\
\hline & $<2{ }^{\circ} \mathrm{C}$ & $2-3{ }^{\circ} \mathrm{C}$ & $>3{ }^{\circ} \mathrm{C}$ & $<2{ }^{\circ} \mathrm{C}$ & $2-3{ }^{\circ} \mathrm{C}$ & $>3{ }^{\circ} \mathrm{C}$ \\
\hline $5 \times 5$ & 71.60 & 17.23 & 11.17 & 76.70 & 14.30 & 9.00 \\
\hline $10 \times 10$ & 79.33 & 13.73 & 6.94 & 83.70 & 11.40 & 4.90 \\
\hline $20 \times 20$ & 83.38 & 12.72 & 3.90 & 90.05 & 7.63 & 2.32 \\
\hline
\end{tabular}

Table 5 shows that using 2007 data as the training data and a $20 \times 20$ window size had the best performance, generating a large area with a difference of $<2{ }^{\circ} \mathrm{C}$ in the predicted versus actual LST.

The root mean square error (RMSE) was also used to analyze the performance of the developed models. Table 6 shows the RMSE for the LST prediction using 2003 and 2007 data at different window sizes.

Table 6: Assessment of the difference between predicted LST and test LST

\begin{tabular}{lcc}
\hline & \multicolumn{2}{c}{ RMSE } \\
\cline { 2 - 3 } Window size & 2003 predict 2015 & 2007 predict 2015 \\
\cline { 2 - 3 } $5 \times 5$ & 2.08 & 1.78 \\
$10 \times 10$ & 1.72 & 1.50 \\
$20 \times 20$ & 1.56 & 1.25 \\
\hline
\end{tabular}

From the observed results it was found that the RMSE decreases when the window size increases. When the 2003 data was used as the training data, the RMSE varied from 2.08 to 1.56, whereas it ranged from 1.78 to 1.25 when the 2007 data was used as the training data. It was concluded that the LST prediction for 2015 using the 2007 data (as the training set) gave better results compared to using the 2003 data (as the training set) as a simulation scenario for coming years. It also demonstrates that the predicted LST using data with a resolution of $600 \mathrm{~m}$ gave a very good forecast in which most of the area had the same LST pattern and value.

\section{LST pattern estimation from absolute LST prediction}

As ultimate objective, LST prediction results described in previous sections will be used to simulate future LST patterns according to different LULC change scenarios, in order to show the features and information the method can provide for urban and territory planners. From the findings in LST prediction validation, we performed the future LST prediction for 2023 using the $20 \times 20$ window size (600 m resolution) and the 2007 data as the training set. The map in Figure 6 shows the LST pattern in low and high growth development scenarios for 
2023. All these maps demonstrate a general LST pattern with a high hot area concentration in the center and cold areas along the river and the northeastern and southeastern sections. However, the hot pattern tends to expand to the northwestern and southwestern parts of the city. These changes mirror the trend in urban expansion. In general, the LST pattern in the period 2015-2023 is characterized by decreases in cold and cool LST areas and increases in hot and very hot areas. Warm LST areas do not substantially change as such areas increase or decrease in a reduced number of zones. According to the LULC change scenarios and LST prediction, high urban growth makes the largest contribution to the increase in the very hot LST area.
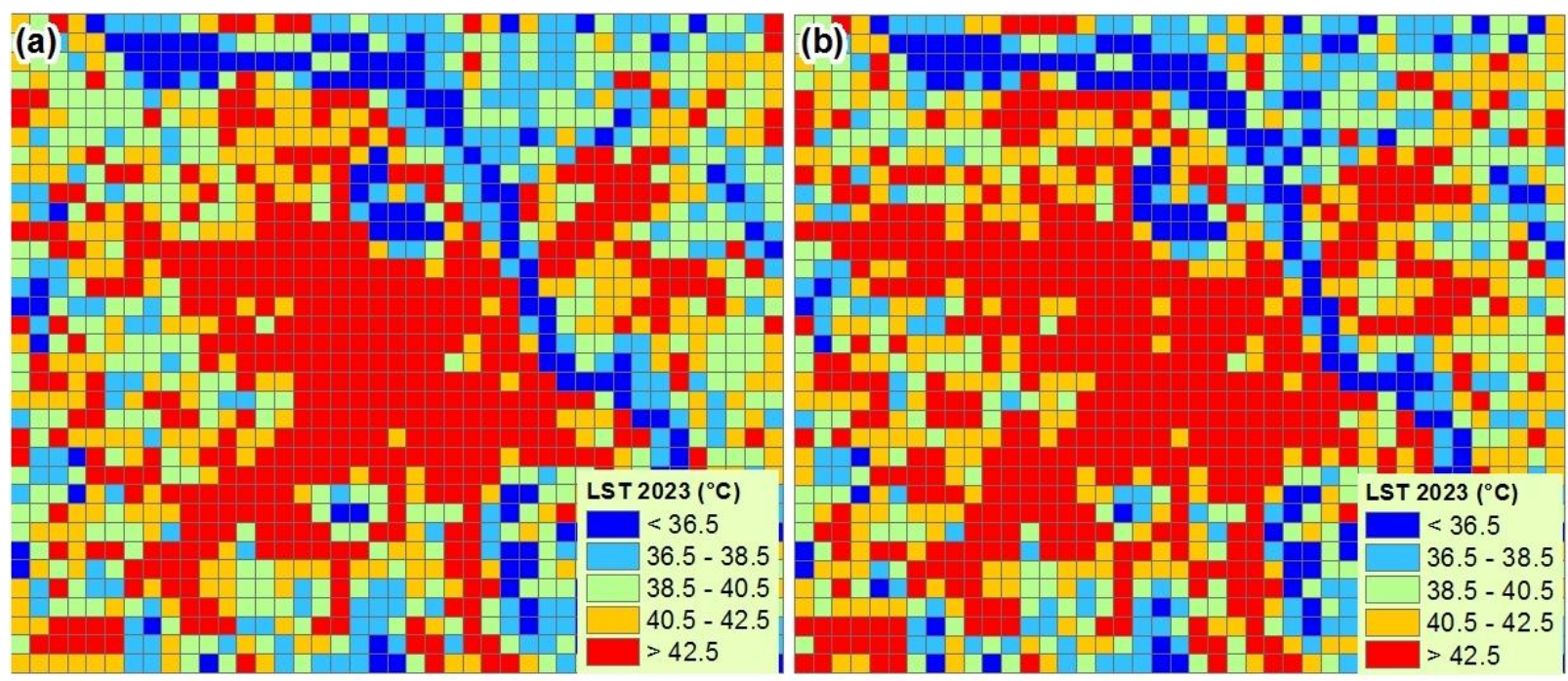

Figure 6: Map of predicted LST in 2023 at different simulation scenarios (a: LST in 2023 in low growth scenario, b: LST in 2023 in high growth scenario).

The absolute predicted LST was then classified into different zones of $2.0{ }^{\circ} \mathrm{C}$ interval (Table 7). A clear trend of change was found from 2015 to 2023 in the sense that the hotter LST zones $\left(40.5{ }^{\circ} \mathrm{C}-42.5{ }^{\circ} \mathrm{C}\right.$ and $\left.>42.5{ }^{\circ} \mathrm{C}\right)$ tend to increase and the colder LST zones $(<36.5$ ${ }^{\circ} \mathrm{C}$ and $36.5{ }^{\circ} \mathrm{C}-38.5{ }^{\circ} \mathrm{C}$ ) tend to decrease. The same trend occurs from low to high growth scenarios in 2023, although with less intensity in the low growth scenario.

Table 7: Area of different LST zones in 2015 and 2023 in and around the study area (hectares)

\begin{tabular}{lrrr}
\hline & \multicolumn{3}{c}{2023} \\
LST zone & 2015 & $\begin{array}{c}\text { Low growth } \\
\text { scenario }\end{array}$ & $\begin{array}{c}\text { High growth } \\
\text { scenario }\end{array}$ \\
\hline$<36.5^{\circ} \mathrm{C}$ & 6732 & 5148 & 5760 \\
$36.5-38.5{ }^{\circ} \mathrm{C}$ & 10440 & 8604 & 7380 \\
$38.5-40.5{ }^{\circ} \mathrm{C}$ & 10800 & 11484 & 9540 \\
$40.5-42.5{ }^{\circ} \mathrm{C}$ & 8676 & 9936 & 11124 \\
$>42.5^{\circ} \mathrm{C}$ & 15012 & 16488 & 17856 \\
\hline
\end{tabular}

The changes in LST patterns through urbanization assessment in the study area show that urban growth severely impacts UHI. This process reduces the agricultural land and non- 
built-up space. Consequently, urbanization leads to the loss of cold and cool areas and the gain of hot and very hot areas. Hence, it is necessary to consider appropriate proportions of green space and open land in cities to mitigate the UHI effect.

\section{Conclusions}

This study presents a comprehensive approach combining linear regression, nonlinear regression, urban landscape analysis using ULAT, hotspot analysis using Getis Ord Gi* statistics to investigate the relationship between LULC change and urbanization and UHI effects. Results from this work provide an effective methodology for characterizing UHI and have significant implications for policy makers and communities by providing a scientific basis for sustainable urban planning and management.

By examining the relationship between LST and NDVI, NDBI within each LULC type, we discovered that the correlation is not always linear since it may vary between each LULC type as well as being subject to the geographic location and season. This finding is consistent with previous UHI studies (Owen et al., 1998; Zhou et al., 2014; Guo et al., 2015). We suggested that local differences need to be concerned to have appropriate conclusion in LULCLST relationship examination.

The analysis of the data showed a nonlinear relationship between LULC and LST, therefore we applied nonlinear regression using KRR and LULC type variables to predict future LST. This method exhibits a promising performance in UHI forecast. The predicted LST confirms that urban growth has severely influenced UHI pattern through expanding the hot area. Our study confirmed that LST prediction performance is strongly depended on the resolution. Our line of research tries to shed some light on the effect of resolution in the capability for regression algorithms to predict LST (Ghosh and Joshi, 2014). In addition, the most suitable is $600 \mathrm{~m}$ that is similar to what was reported in Song et al. (2014).

We found that hotspot analysis using Getis Ord Gi* statistics is an appropriate method to examine changes in LST patterns through time. The identification of hot spot or cold spot areas by such method does not depend on whether the mean surface temperature is high or low so the effect of different LST values throughout time is reduced. In general, more than $20 \%$ of the city area is always warmer whereas less than $10 \%$ of the city area is always colder than the mean zonal LST. Hot spots tend to increase through time (from $27.95 \%$ in 2003 to $34.61 \%$ in 2015) and strongly correlate with urban expansion.

We suggested that urban landscape analysis using ULAT is an innovative method for investigating the impact of urbanization on UHI. The method is quite simple to implement but brings the crucial conclusion that UHI is severely influenced by urban landscape composition. From the perspective of land use planning and urban management, it is recommend that planners and policy makers should pay serious attention to future land use policies that maintain a relevant proportion of public space, green areas, and water in city LULC structures. 
Similar findings have been reported by Onishi et al. (2010), Oliveira et al. (2011), Nichol and To. (2012), Feyisa et al. (2014), Di Leo et al. (2016). Interestingly, we found that the UHI effect is also strongly affected by the type of urban development. This conclusion is remained as one of the early finding in relation to UHI- spatial pattern of urbanization relationship.

Our study has provided a comprehensive methodology to characterize UHI in a tropical city in the context of urbanization. However, we suggested that the following limitations should be considered in future research. Using higher resolution imagery for LULC classification may give a better explanation of LULC composition-LST correlation, as well as results that are more practical for urban planners. To have deeper insight into the nonlinear correlation between LULC and LST in urban area, further study needs to include urban morphology as an important indicator. Other nonlinear regression methods and potential window sizes may also need to be tested for LST prediction to obtain more comprehensive and concluding results.

\section{Acknowledgments}

First, the authors would like to thank the European Commission and the Erasmus Mundus Consortium for providing the master scholarship in Geospatial Technologies. We acknowledge the USGS-NASA due to their freely accessible Landsat data. Thanks are also due to the Laboratory for Geographic Information Analysis (Department of Geography, Hanoi National University of Education) for providing valuable tools and software. This work has also been partially supported by the Spanish Ministry of Economy under project ESP2013-48458-C4-3P. Finally, we also extend our gratitude to the anonymous reviewers of this manuscript for their helpful suggestions.

\section{REFERENCES}

Adams, M. P., \& Smith, P. L. (2014). A systematic approach to model the influence of the type and density of vegetation cover on urban heat using remote sensing. Landscape and Urban Planning, 132, 47-54.

Ahmed, B., Kamruzzaman, M., Zhu, X., Rahman, M. S., \& Choi, K. (2013). Simulating land cover changes and their impacts on land surface temperature in Dhaka, Bangladesh. Remote Sensing, 5(11), 5969-5998.

Angel, S., Parent, J., \& Civco, D. L. (2012). The fragmentation of urban landscapes: global evidence of a key attribute of the spatial structure of cities, 1990-2000. Environment and Urbanization, 24(1), 249-283. 
Baker, W. L. (1989). A review of models of landscape change. Landscape ecology, 2(2), 111133.

Barsi, J. A., Schott, J. R., Palluconi, F. D., \& Hook, S. J. (2005). Validation of a web-based atmospheric correction tool for single thermal band instruments. In Optics \& Photonics 2005 (pp. 58820E-58820E). International Society for Optics and Photonics.

Burchfield, M., Overman, H. G., Puga, D., \& Turner, M. A. (2006). Causes of sprawl: A portrait from space. The Quarterly Journal of Economics, 587-633.

Chun, B., \& Guldmann, J. M. (2014). Spatial statistical analysis and simulation of the urban heat island in high-density central cities. Landscape and urban planning, 125, 76-88.

Coseo, P., \& Larsen, L. (2014). How factors of land use/land cover, building configuration, and adjacent heat sources and sinks explain Urban Heat Islands in Chicago. Landscape and Urban Planning, 125, 117-129.

Craglia, M., Haining, R., \& Wiles, P. (2000). A comparative evaluation of approaches to urban crime pattern analysis. Urban Studies, 37(4), 711-729.

Dihkan, M., Karsli, F., Guneroglu, A., \& Guneroglu, N. (2015). Evaluation of surface urban heat island (SUHI) effect on coastal zone: The case of Istanbul Megacity. Ocean \& Coastal Management.

Di Leo, N., Escobedo, F. J., \& Dubbeling, M. (2016). The role of urban green infrastructure in mitigating land surface temperature in Bobo-Dioulasso, Burkina Faso. Environment, Development and Sustainability, 18(2), 373-392.

Feng, H., Zhao, X., Chen, F., \& Wu, L. (2014). Using land use change trajectories to quantify the effects of urbanization on urban heat island. Advances in Space Research, 53(3), 463-473. Feyisa, G. L., Dons, K., \& Meilby, H. (2014). Efficiency of parks in mitigating urban heat island effect: An example from Addis Ababa. Landscape and Urban Planning, 123, 87-95. Gajović, V., \& Todorović, B. (2013). Spatial and temporal analysis of fires in Serbia for period 2000-2013. In International Conference "Natural Hazards-Links between Science and Practice," J. Geogr. Inst. Jovan Cvijic (Vol. 63, pp. 297-312).

Ghosh, A., \& Joshi, P. K. (2014). Hyperspectral imagery for disaggregation of land surface temperature with selected regression algorithms over different land use land cover scenes. ISPRS Journal of Photogrammetry and Remote Sensing, 96, 76-93.

Guo, G., Wu, Z., Xiao, R., Chen, Y., Liu, X., \& Zhang, X. (2015). Impacts of urban biophysical composition on land surface temperature in urban heat island clusters. Landscape and Urban Planning, 135, 1-10. 
Guo, G., Zhou, X., Wu, Z., Xiao, R., Chen, Y., 2016. Characterizing the impact of urban morphology heterogeneity on land surface temperature in Guangzhou, China. Environmental Modelling \& Software 84, 427-439.

Grimmond, S. (2007). Urbanization and global environmental change: local effects of urban warming. The Geographical Journal, 173(1), 83-88.

Imhoff, M. L., Zhang, P., Wolfe, R. E., \& Bounoua, L. (2010). Remote sensing of the urban heat island effect across biomes in the continental USA. Remote Sensing of Environment, 114(3), 504-513.

Junxiang, L., Conghe, S., Lu, C., Feige, Z., Xianlei, M., Jianguo, W. (2011). Impacts of landscape structure on surface urban heat islands: A case study of Shanghai, China. Remote Sensing of Environment, 115, 3249-3263.

Kikegawa, Y., Genchi, Y., Yoshikado, H., \& Kondo, H. (2003). Development of a numerical simulation system toward comprehensive assessments of urban warming countermeasures including their impacts upon the urban buildings' energy-demands. Applied Energy, 76(4), 449466.

Kourtidis, K., Georgoulias, A. K., Rapsomanikis, S., Amiridis, V., Keramitsoglou, I., Hooyberghs, H., \& Melas, D. (2015). A study of the hourly variability of the urban heat island effect in the Greater Athens Area during summer. Science of The Total Environment, 517, 162177.

Kumar, K. S., Bhaskar, P. U., \& Padmakumari, K. (2012). Estimation of land surface temperature to study urban heat island effect using LANDSAT ETM+ image. International journal of Engineering Science and technology, 4(2), 771-778.

Kumar, D., \& Shekhar, S. (2015). Statistical analysis of land surface temperature-vegetation indexes relationship through thermal remote sensing. Ecotoxicology and environmental safety, $121,39-44$.

Liu, L., \& Zhang, Y. (2011). Urban heat island analysis using the Landsat TM data and ASTER data: A case study in Hong Kong. Remote Sensing, 3(7), 1535-1552.

Luyssaert, S., Jammet, M., Stoy, P. C., Estel, S., Pongratz, J., Ceschia, E., \& Dolman, A. J. (2014). Land management and land-cover change have impacts of similar magnitude on surface temperature. Nature Climate Change, 4(5), 389-393.

McCarville, D., Buenemann, M., Bleiweiss, M., \& Barsi, J. (2011). Atmospheric correction of Landsat thermal infrared data: a calculator based on North American Regional Reanalysis (NARR) data. In Proc. of the American Society for Photogrammetry and Remote Sensing Conf (p. 12). 
Meineke, E. K., Dunn, R. R., \& Frank, S. D. (2014). Early pest development and loss of biological control are associated with urban warming. Biology letters, 10(11), 20140586.

Mohan, M., \& Kandya, A. (2015). Impact of urbanization and land-use/land-cover change on diurnal temperature range: A case study of tropical urban airshed of India using remote sensing data. Science of the Total Environment, 506, 453-465.

Myint, S. W., Wentz, E. A., Brazel, A. J., \& Quattrochi, D. A. (2013). The impact of distinct anthropogenic and vegetation features on urban warming. Landscape Ecology, 28(5),959-978.

Nichol, J. E., \& To, P. H. (2012). Temporal characteristics of thermal satellite images for urban heat stress and heat island mapping. ISPRS journal of photogrammetry and remote sensing, 74, 153-162.

Niem, T.H., Wen, L., Renee, L. N., Darlene, O.G., Duy,T.X. Southeast Asia 2050-2100: Imagining New Lifeways/Lifestyles. In After Climate Change and Culture-shift: Imagining a World, ed. J. Norwine. New York, NY: Springer, 2013.

Ogashawara, I., \& Bastos, V. D. S. B. (2012). A quantitative approach for analyzing the relationship between urban heat islands and land cover. Remote Sensing, 4(11), 3596-3618.

Oke, T. R. (1982). The energetic basis of the urban heat island. Quarterly Journal of the Royal Meteorological Society, 108(455), 1-24.

Oliveira, S., Andrade, H., \& Vaz, T. (2011). The cooling effect of green spaces as a contribution to the mitigation of urban heat: A case study in Lisbon. Building and Environment, 46(11), 2186-2194.

Onishi, A., Cao, X., Ito, T., Shi, F., \& Imura, H. (2010). Evaluating the potential for urban heat-island mitigation by greening parking lots. Urban forestry \& Urban greening, 9(4), 323 332.

Ord, J. K., \& Getis, A. (1995). Local spatial autocorrelation statistics: distributional issues and an application. Geographical analysis, 27(4), 286-306.

Owen, T. W., Carlson, T. N., \& Gillies, R. R. (1998). An assessment of satellite remotelysensed land cover parameters in quantitatively describing the climatic effect of urbanization. International journal of remote sensing, 19(9), 1663-1681.

Palit, A. K., \& Popovic, D. (2006). Computational intelligence in time series forecasting: theory and engineering applications. Springer Science \& Business Media.

Plocoste, T., Jacoby-Koaly, S., Molinié, J., \& Petit, R. H. (2014). Evidence of the effect of an urban heat island on air quality near a landfill. Urban Climate, 10, 745-757.

Quattrochi, D. A., \& Luvall, J. C. (1999). Thermal infrared remote sensing for analysis of landscape ecological processes: methods and applications. Landscape ecology, 14(6), 577-598. 
Qiao, Z., Tian, G., \& Xiao, L. (2013). Diurnal and seasonal impacts of urbanization on the urban thermal environment: A case study of Beijing using MODIS data. ISPRS journal of photogrammetry and remote sensing, 85, 93-101.

Radhi, H., Fikry, F., \& Sharples, S. (2013). Impacts of urbanisation on the thermal behaviour of new built up environments: A scoping study of the urban heat island in Bahrain. Landscape and Urban Planning, 113, 47-61.

Rizwan, A. M., Dennis, L. Y., \& Chunho, L. I. U. (2008). A review on the generation, determination and mitigation of Urban Heat Island. Journal of Environmental Sciences, 20(1), $120-128$.

Rotem-Mindali, O., Michael, Y., Helman, D., \& Lensky, I. M. (2015). The role of local land use on the urban heat island effect of Tel Aviv as assessed from satellite remote sensing. Applied Geography, 56, 145-153.

Saunders, C., Gammerman, A., \& Vovk, V. (1998). Ridge regression learning algorithm in dual variables. In (ICML-1998) Proceedings of the 15th International Conference on Machine Learning (pp. 515-521).

Shao, G., \& Wu, J. (2008). On the accuracy of landscape pattern analysis using remote sensing data. Landscape Ecology, 23(5), 505-511.

Sobrino, J. A., Jiménez-Muñoz, J. C., \& Paolini, L. (2004). Land surface temperature retrieval from LANDSAT TM 5. Remote Sensing of environment, 90(4), 434-440.

Song, J., Du, S., Feng, X., \& Guo, L. (2014). The relationships between landscape compositions and land surface temperature: quantifying their resolution sensitivity with spatial regression models. Landscape and Urban Planning, 123, 145-157.

Songchitruksa, P., \& Zeng, X. (2010). Getis-Ord spatial statistics to identify hot spots by using incident management data. Transportation Research Record: Journal of the Transportation Research Board, (2165), 42-51.

Taha, H. (1997). Urban climates and heat islands: albedo, evapotranspiration, and anthropogenic heat. Energy and buildings, 25(2), 99-103.

Tempfli, K., Kerle, N., Huurneman, G. C., \& Janssen, L. L. (2009). Principles of Remote Sensing. An introductory textbook.

Walawender, J. P., Szymanowski, M., Hajto, M. J., \& Bokwa, A. (2014). Land surface temperature patterns in the urban agglomeration of Krakow (Poland) derived from Landsat7/ETM+ data. Pure and Applied Geophysics, 171(6), 913-940.

Wang, K., Wang, J., Wang, P., Sparrow, M., Yang, J., \& Chen, H. (2007). Influences of urbanization on surface characteristics as derived from the Moderate-Resolution Imaging 
Spectroradiometer: A case study for the Beijing metropolitan area. Journal of Geophysical Research: Atmospheres, 112(D22).

Weng, Q., Lu, D., \& Schubring, J. (2004). Estimation of land surface temperature-vegetation abundance relationship for urban heat island studies. Remote sensing of Environment, 89(4), 467-483.

Weng, Q. (2009). Thermal infrared remote sensing for urban climate and environmental studies: Methods, applications, and trends. ISPRS Journal of Photogrammetry and Remote Sensing, 64(4), 335-344.

Wolf, T., \& McGregor, G. (2013). The development of a heat wave vulnerability index for London, United Kingdom. Weather and Climate Extremes, 1, 59-68.

Wulder, M., \& Boots, B. (1998). Local spatial autocorrelation characteristics of remotely sensed imagery assessed with the Getis statistic. International Journal of Remote Sensing, 19(11), 2223-2231.

$\mathrm{Xu}, \mathrm{H}$. (2006). Modification of normalised difference water index (NDWI) to enhance open water features in remotely sensed imagery. International Journal of Remote Sensing, 27(14), 3025-3033.

Yonezawa, G. 2009. Generation of DEM for Urban Transformation of Hanoi, Vietnam. Kyoto Working Papers on Area Studies 62(60), 1-10.

Yuan, F., \& Bauer, M. E. (2007). Comparison of impervious surface area and normalized difference vegetation index as indicators of surface urban heat island effects in Landsat imagery. Remote Sensing of Environment, 106(3), 375-386.

Zhang, Y., Odeh, I. O., \& Han, C. (2009). Bi-temporal characterization of land surface temperature in relation to impervious surface area, NDVI and NDBI, using a sub-pixel image analysis. International Journal of Applied Earth Observation and Geoinformation, 11(4), 256264.

Zhou, W., Qian, Y., Li, X., Li, W., \& Han, L. (2014). Relationships between land cover and the surface urban heat island: seasonal variability and effects of spatial and thematic resolution of land cover data on predicting land surface temperatures. Landscape ecology, 29(1), 153-167. CLEAR, 2015. Urban Landscape Analysis Tool. http://clear.uconn.edu/tools/ugat/index.htm. Accessed 15 October 2015

ESRI, 2016. How Hot Spot Analysis (Getis-Ord Gi*) works? http://pro.arcgis.com/en/proapp/tool-reference/spatial-statistics/h-how-hot-spot-analysis-getis-ord-gi-spatial-stati.htm. Accessed 16 February 2016. 
HSO, 2013a. Don vi hanh chinh, dat dai, khi hau.

http://thongkehanoi.gov.vn/uploads/files/source/NGTK\%202013\%20-

DVHC\%20dat\%20dai\%20va\%20khi\%20hau.pdf). Accessed 13 September 2015.

HSO, 2013b. Dan so va lao dong.

http://thongkehanoi.gov.vn/uploads/files/source/NGTK\%202013\%20-

Dan\%20so\%20lao\%20dong.pdf). Accessed 13 September 2015.

Landsat, N. A. S. A. (7). Science Data Users Handbook. 2011-03-11.

http://landsathandbook.gsfc. nasa. gov/inst_cal/prog_sect8_2. html. Accessed 18 October 2015.

Landsat, N. A. S. A. (8). Science Data Users Handbook. 2015-june.

http://landsat.usgs.gov/18handbook.php. Accessed 23 September 2015.

NCHMF, 2015. Thoi tiet Hanoi. http://www.nchmf.gov.vn/Web/vi-VN/43/Default.aspx.

Accessed 20 December 2015.

VGP, 2016. Quy hoach xay dung Vung Thu Do Hanoi den nam 2030 va tam nhin den 2050.

http://vanban.chinhphu.vn/portal/page/portal/chinhphu/hethongvanban?class_id=2\&mode=deta il\&document_id=184573. Accessed 10 May 2016.

\section{APPENDICES}

Appendix 1: LULC map of Hanoi inner city in 2003

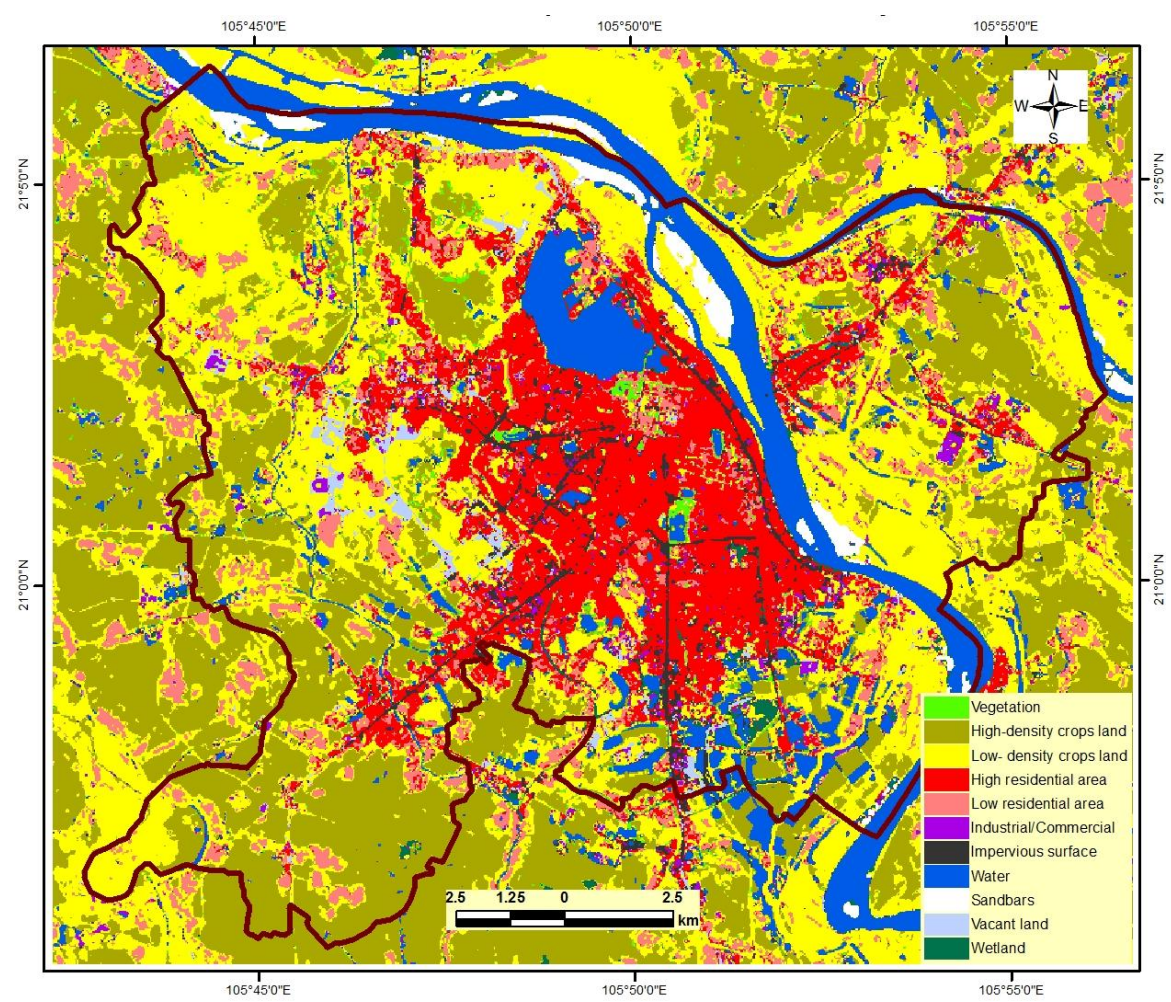


Appendix 2: LULC map of Hanoi inner city in 2007

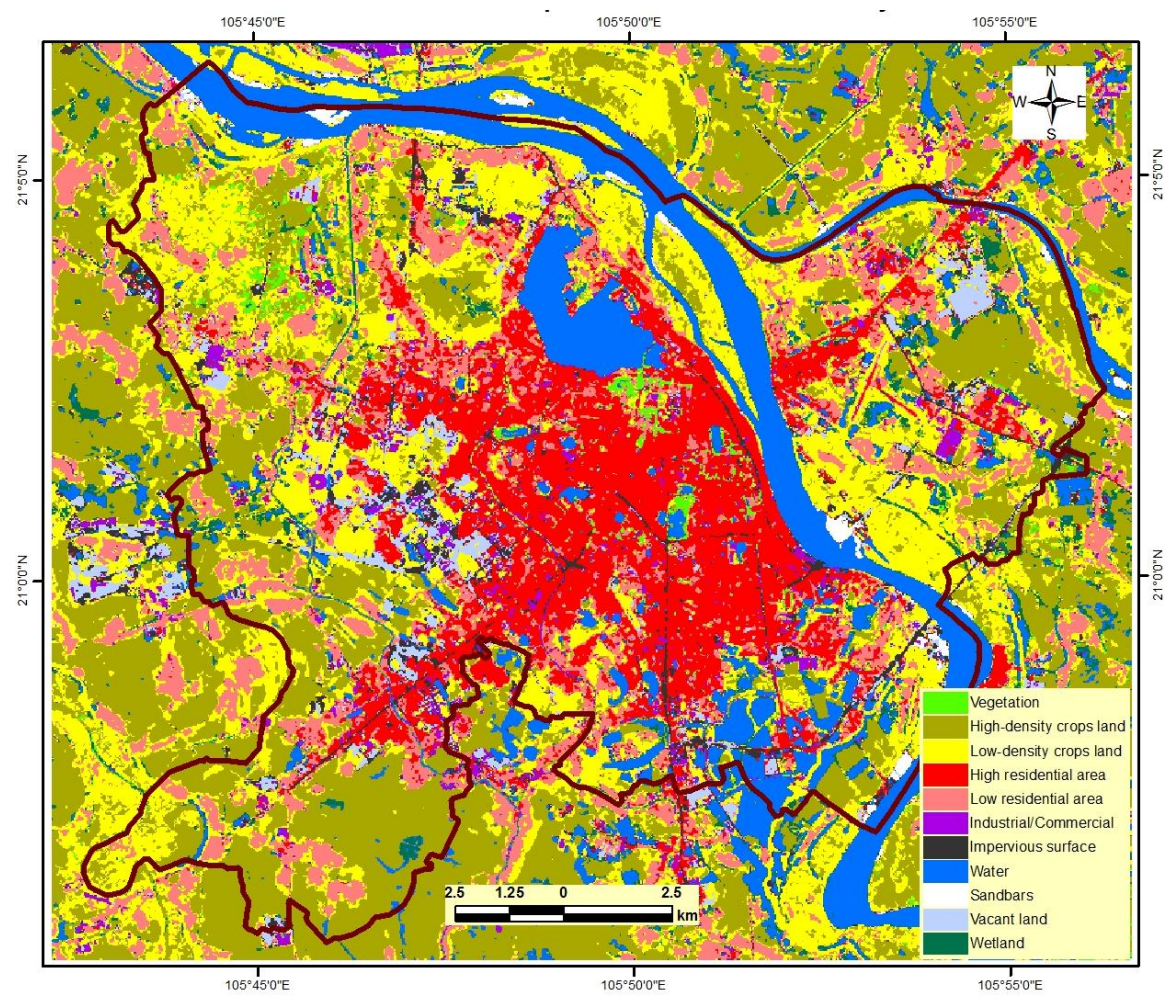

Appendix 3: LULC map of Hanoi inner city in 2015

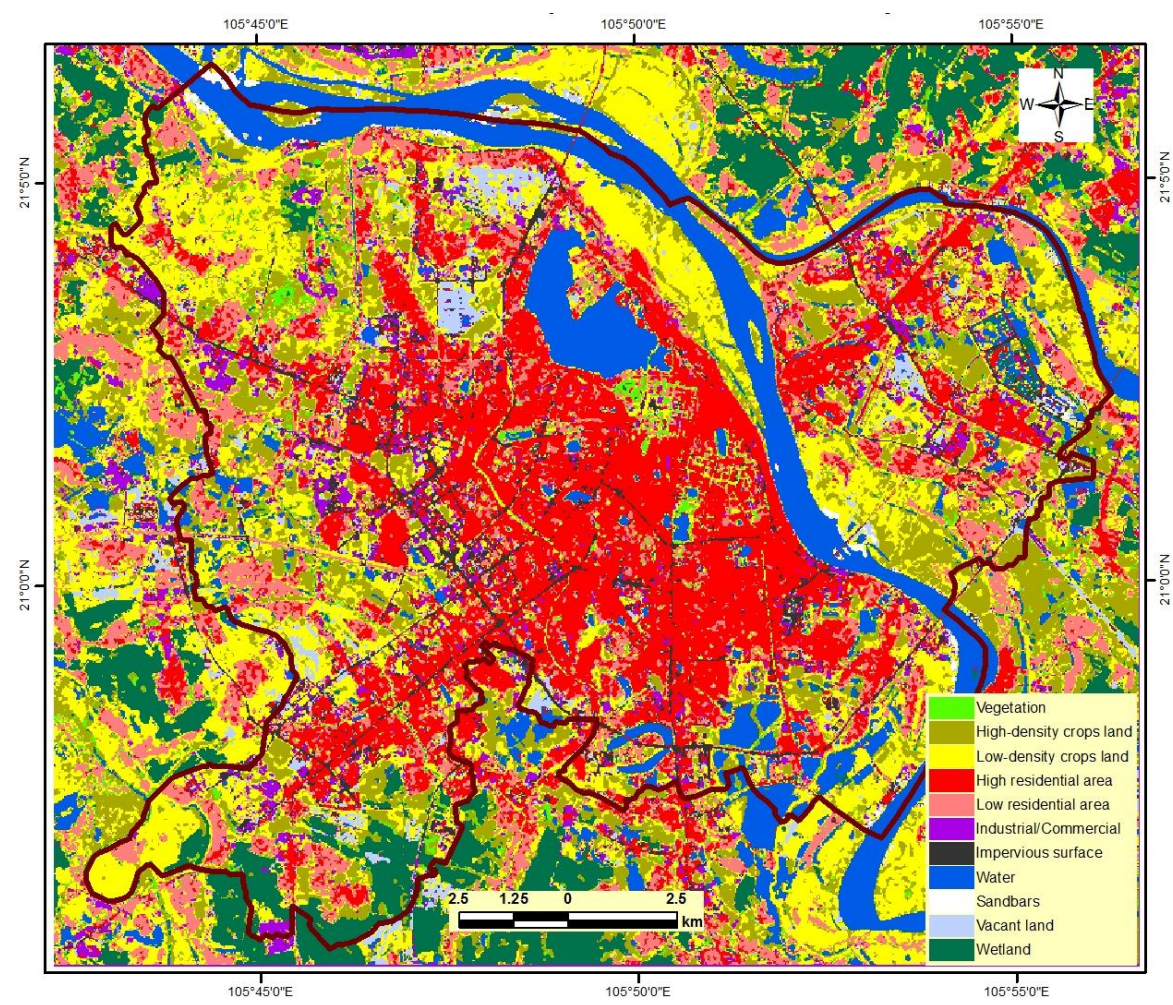

